\title{
Perilaku Undrained Strength Pada Tanah Lempung Ekspansif Tidak Terganggu Selama Proses Pembasahan Dan Pengeringan Berhubungan Dengan Retak Permukaan Dan Suction
}

\author{
*Elim Ester ${ }^{1}$ \\ ${ }^{1}$ Program Studi Teknik Sipil,Fakultas Teknik, Universitas Flores, Ende \\ *) Corresponce email: esterelim9@gmail.com
}

\begin{abstract}
ABSTRAK
Tanah lempung ekspansif sangat mudah mengalami perubahan volume akibat perubahan kadar air. Saat tanah mengalami pengeringan tanah akan menyusut dan retak, jika mengalami pembasahan tanah akan mengembang. Akibat dari perubahan kadar air dalam tanah berpengaruh pada suction, retak permukaan dan undrained shear strength. Penelitian ini menggunakan benda uji tanah ekspansif undisturb diambil dari daerah Citraland di Surabaya, Indonesia. Dilakukan pengujian awal untuk mengetahui sifat fisik dan mekanik tanah. Selanjutnya dilakukan proses pengeringan dimulai saat kondisi inisial dengan kadar air (Wc) 57,79\% langsung dikeringkan pada suhu ruang sampai dengan kadar air $\left(W_{c}\right)$ 10,01\%. Kemudian dilakukan proses pembasahan dari kadar air $\left(W_{c}\right)$ 10,01\% dengan penambahan air sebesar 25\%, 75\% dan 100\% dari kadar air inisial. Dari Pengamatan evolusi retak permukaan pada proses pengeringan dan pembasahan ditentukan kondisi kadar air sebagai acuan untuk pengujian undrained triaksial shear strength dan suction. Hasil dari penelitian ini menunjukkan bahwa retak permukaan mulai terjadi saat peningkatan nilai suction mencapai 178 kali saat pengeringan, saat pembasahan tanah menjadi rusak (damage). Nilai kohesi maksimun $42 \mathrm{kPa}$ terjadi pada kadar air (Wc) 22, \% saat pengeringan dan $28 \mathrm{kPa}$ saat kadar air (Wc) $45 \%$ pada proses pembasahan. Sifat tanah lempung ekspansif undisturb berubah menyerupai batuan dengan nilai sudut geser dalam sebesar $\phi=62,6^{\circ}$ saat pengeringan. Tanah ekspansif dari penelitian ini adalah tanah unsaturated.
\end{abstract}

Kata kunci : tanah ekspansif, retak permukaan, tidakjenuh, undrained strength, suction

\section{PENDAHULUAN}

Tanah ekspansif adalah tanah yang mudah mengalami perubahan volume saat terjadi perubahan kadar air. Tanah jenis ini mempunyai karakteristik mengembang jika kadar air meningkat selain itu tanah ini menyusut dan retak pada permukaan jika kadar air menurun Chen Fu Hua (1975). Jika terjadi pengeringan yang kuat tanah ini menjadi getas / mengeras dan retak, Saat tegangan kapiler melebihi kohesi atau tegangan tarik dari tanah ekspansif, maka tanah akan mengalami retakan Holtz, R.D and Kovacs, W.D (1981). Selama perilaku tidak stabil, tanah lempung ekspansif menyebabkan kerusakan pada struktur konstruksi diatasnya. Beberapa kerusakan yang terjadi adalah penurunan pondasi yang mengakibatkan keretakan pada gedung, jalan menjadi bergelombang, kelongsoran pada timbunan dan lain-lain Holtz,W. G. and Gibbs,J.J (1956).

Penelitian tentang tanah ekspansif telah dilakukan oleh beberapa peneliti yang menggunakan tanah ekspansif remolded dalam kondisi slurry. Penelitian tanah ekspansif remolded yang diambil dari Citraland di Surabaya dilakukan oleh Badawi dan Indarto (2010), sehingga hasil dari penelitian ini dapat dibandingkan.

Penelitian ini menggunakan tanah ekspansif undisturb dalam kondisi plastis untuk meninjau perilaku tanah ekspansif selama proses pengeringan dan pembasahan terkait undrained shear strength, suction dan retak permukaan. Tanah undisturb menunjukkan sifat tanah yang mewakili kondisi asli dilapangan.

\section{Bahan dan Metode Penelitian}

Tanah dari penelitian ini diambil dari Citraland di Surabaya, Indonesia dalam kondisi undisturb. Pertama dilakukan pengujian sifat fisik properties dan mekanikal tanah kondisi inisial. Kedua dilakukan proses 
pengeringan dari kondisi inisial kadar air 57,79\% langsung dikeringkan pada suhu ruang sampai pada kadar air $10,01 \%$ dan proses pembasahan dengan menambah air sebanyak $25 \%, 75 \%$ dan $100 \%$ dari kadar air inisial. Saat pengamatan retak permukaan selama proses pengeringan ditentukan kadar air yang dipakai sebagai acuan untuk pengujian undrained triaksial shear strength dan suction.

Hasil pengujian properties tanah Citraland pada kondisi inisial ditunjukkan pada Tabel 1. Dari tabel 1, dapat dilihat kandungan clay sangat dominan $(68,3 \%)$ dan indeks plastis cukup tinggi $(78,87 \%)$ derajat kejenuhan 97,97\% ini menunjukkan kondisi tanah adalah pseudo saturated.

Tabel 1. Hasil pengujian sifat fisik tanah lempung ekspansif kondisi inisal

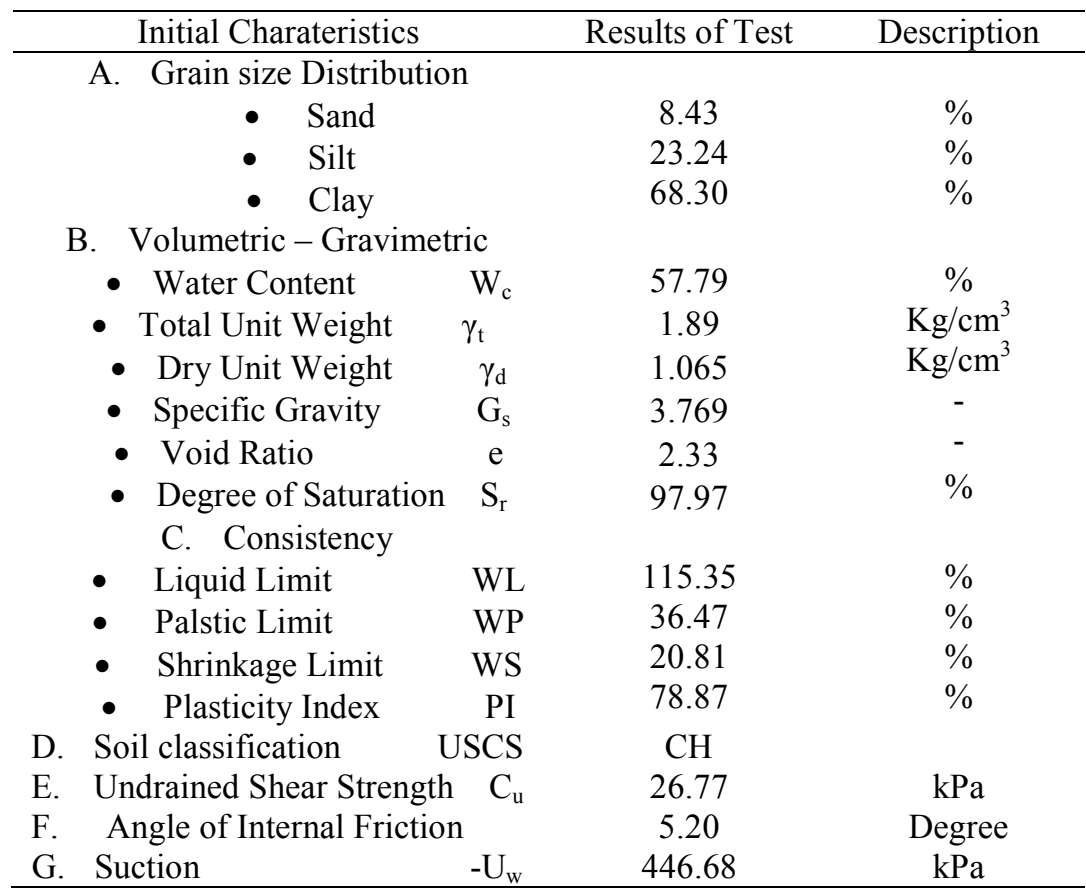

\section{HASIL DAN PEMBAHASAN}

\section{Proses Pengeringan}

Hasil pengujian sifat fisik dan mekanikal tanah dari proses pengeringan dan pembasahan ditunjukkan pada Tabel 2. dan dipresentasikan pada Soil Water Characteristic Curve (SWCC) dapat dilihat pada Gambar 1. Hasil dari penelitian ini tidak menunjukkan adanya histerisis yang terjadi pada Soil Water Characteristic Curve (SWCC), kurva alur pembasahan selalu kembali menyatu pada kurva alur pengeringan. Hal ini menunjukkan bahwa tanah telah mengalami kembang susut berulang kali dilapangan akibat musim panas dan musim hujan, sehingga pada penelitian ini pengembangan tanah akibat pembasahan tidak sebesar tanah remolded Badawi, S and Indarto. (2010) dan Elim E, Soemitro,R.A.A and Indarto (2019).

Gambar 1.A adalah kurva penyusutan dan pengembangan tanah, terlihat angka pori yang mengecil pada saat proses pengeringan menunjukkan benda uji mengalami penyusutan. Pada saat pembasahan terjadi kenaikan angka pori yang alur grafiknya menyatu dengan alur grafik pengeringan. Hal ini menunjukkan sifat dari tanah ekspansif yang sangat kering pada saat pembasahan akan terjadi pengembangan Chen Fu Hua (1975). Kadar air inisial tanah ekspansif saat pembasahan sangat menentukan besarnya pengembangan yang terjadi Chen Fu Hua (1975) dan Indarto (2012). Pada gambar 1.B. menunjukkan hubungan antara angka pori dan 
tegangan air pori negative, terlihat saat pengeringan penurunan angka pori menyebabkan kenaikan tegangan air pori tanah yang sangat besar menyebabkan penyusutan pada tanah dan retak permukaan terjadi. Saat pembasahan angka pori meningkat tegangan air pori menurun menyebabkan tanah mengembang. Tanah menjadi jenuh saat ada peningkatan kadar air lebih besar dari $22 \%$, jika lebih kecil $22 \%$ tanah menjadi tidak jenuh. Air entry value pada kadar air $22 \%$ saat tegangan air pori negative $25.000 \mathrm{kPa}$ saat pengeringan Elim E, Soemitro,R.A.A and Indarto (2019)

Tabel 2. Hasil pengujian karakteristik sifat fisik dan mekanikal akibat proses pengeringan dan pembasahan

\begin{tabular}{lcccccccc}
\hline & $\begin{array}{c}\text { Water } \\
\text { Content }\end{array}$ & $\begin{array}{c}\text { Water } \\
\text { Content } \\
\text { of Filter } \\
\text { Paper }\end{array}$ & $\begin{array}{c}\text { Unit } \\
\text { Weight }\end{array}$ & $\begin{array}{c}\text { Dry } \\
\text { Unit } \\
\text { Weight }\end{array}$ & $\begin{array}{c}\text { Void } \\
\text { Ratio }\end{array}$ & $\begin{array}{c}\text { Degree } \\
\text { of } \\
\text { Saturati } \\
\text { on }\end{array}$ & $\begin{array}{c}\text { Suctio } \\
\mathbf{n}\end{array}$ & $\begin{array}{c}\text { Negative } \\
\text { pore water } \\
\text { pressure }\end{array}$ \\
& $\begin{array}{c}\text { Wc } \\
\%\end{array}$ & $\begin{array}{c}\text { Wf } \\
\text { \% }\end{array}$ & $\begin{array}{c}\mathbf{V}_{\mathbf{t}} \\
\mathrm{gr} / \mathrm{cc}\end{array}$ & $\begin{array}{c}\mathbf{V}_{\mathrm{d}} \\
\mathrm{gr} / \mathrm{cc}\end{array}$ & $\mathbf{e}$ & $\begin{array}{c}\text { Sr } \\
\%\end{array}$ & $\mathbf{p F}$ & $\begin{array}{c}\text {-Uw } \\
\mathrm{kPa}\end{array}$ \\
\hline Initial & 57.79 & 44.4 & 1.804 & 1.143 & 2.30 & 94.84 & 3.650 & 446.68 \\
Drying 1 & 26.78 & 24.7 & 1.923 & 1.517 & 1.48 & 67.99 & 5.200 & $15,848.93$ \\
Drying 2 & 16.37 & 15.2 & 2.024 & 1.739 & 1.17 & 52.88 & 5.900 & $79,432.82$ \\
Drying 3 & 12.79 & 11.2 & 2.062 & 1.828 & 1.06 & 45.40 & 6.400 & $251,188.64$ \\
Drying 4 & 11.92 & 10.0 & 2.116 & 1.891 & 0.99 & 45.22 & 6.500 & $316,227.77$ \\
Drying 5 & 10.61 & 9.8 & 2.124 & 1.921 & 0.96 & 41.54 & 6.600 & $398,107.17$ \\
Drying 6 & 10.01 & 9.7 & 2.173 & 1.975 & 0.91 & 41.54 & 6.700 & $501,187.23$ \\
Wetting 25\% & 16.33 & 22.2 & 1.941 & 1.669 & 1.26 & 48.89 & 5.600 & $39,810.72$ \\
Wetting 75\% & 44.63 & 40.0 & 1.675 & 1.158 & 2.25 & 74.63 & 4.200 & $1,584.89$ \\
Wetting 100\% & 58.09 & 45.5 & 1.525 & 0.965 & 2.91 & 75.30 & 3.600 & 398.11 \\
\hline
\end{tabular}

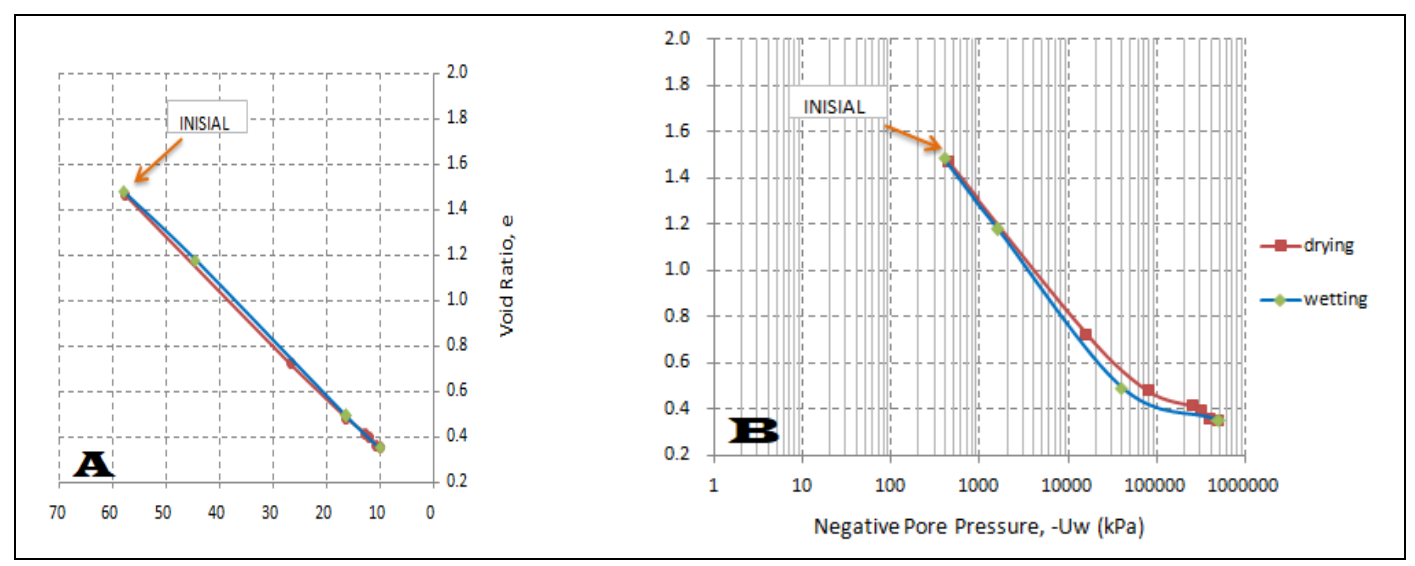




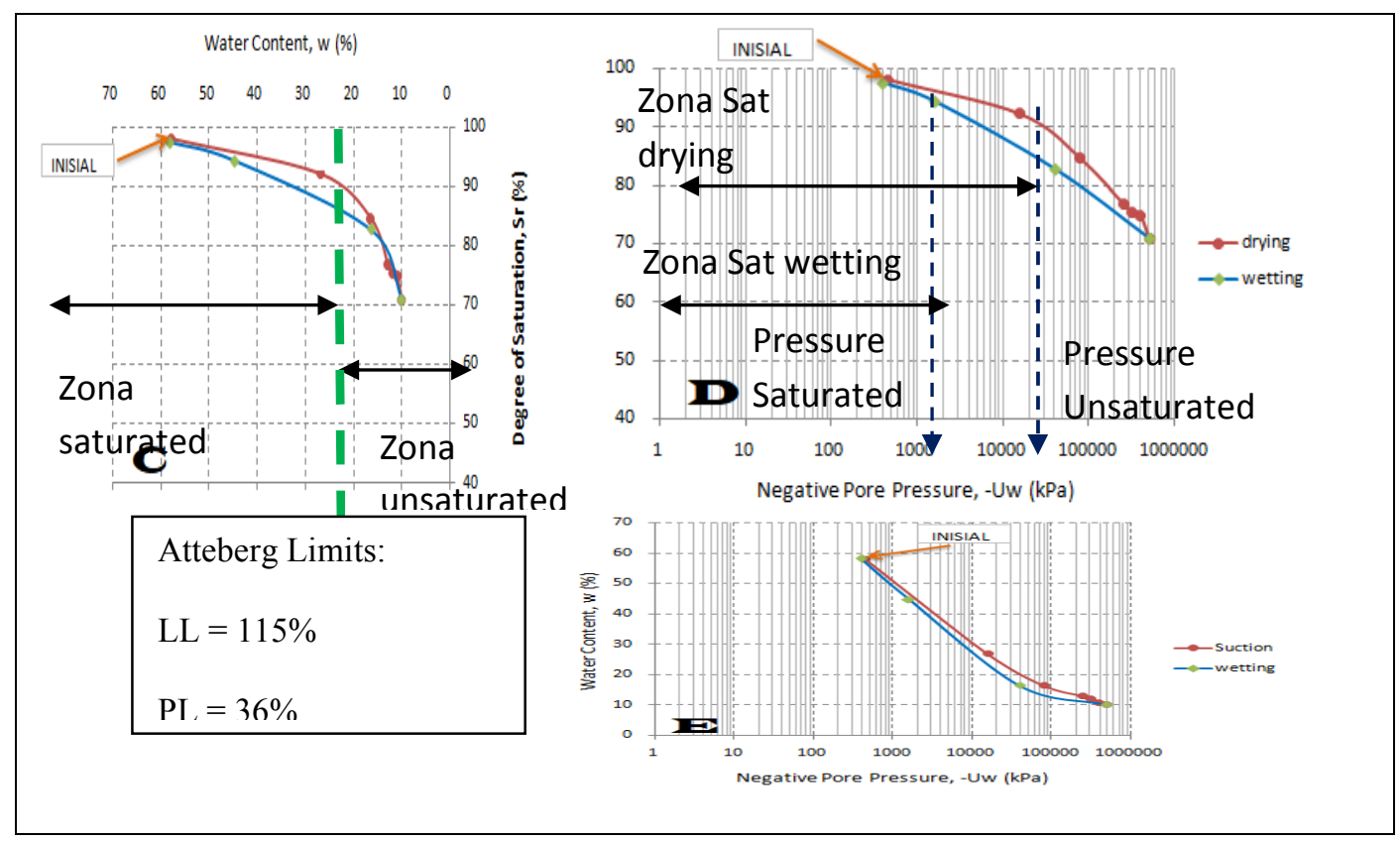

Gambar 1. Soil Water Characteristic Curve (SWCC) tanah ekspansif Undisturb dari Citraland di Surabaya.

\section{Retak permukaan selama proses pengeringan}

Pada gambar 2. Menunjukkan foto retak permukaan selama proses pengeringan yang dilakukan dengan menggunakan mikroskop type SZM-45B2 dengan kamera digital eyepiece type FTV-B pembesaran 200x dan tambahan pembesaran maksimal 90x. Tiap foto menunjukkan retak pada tempat yang berbeda pada permukaan benda uji yang sama pada tiap kondisi.

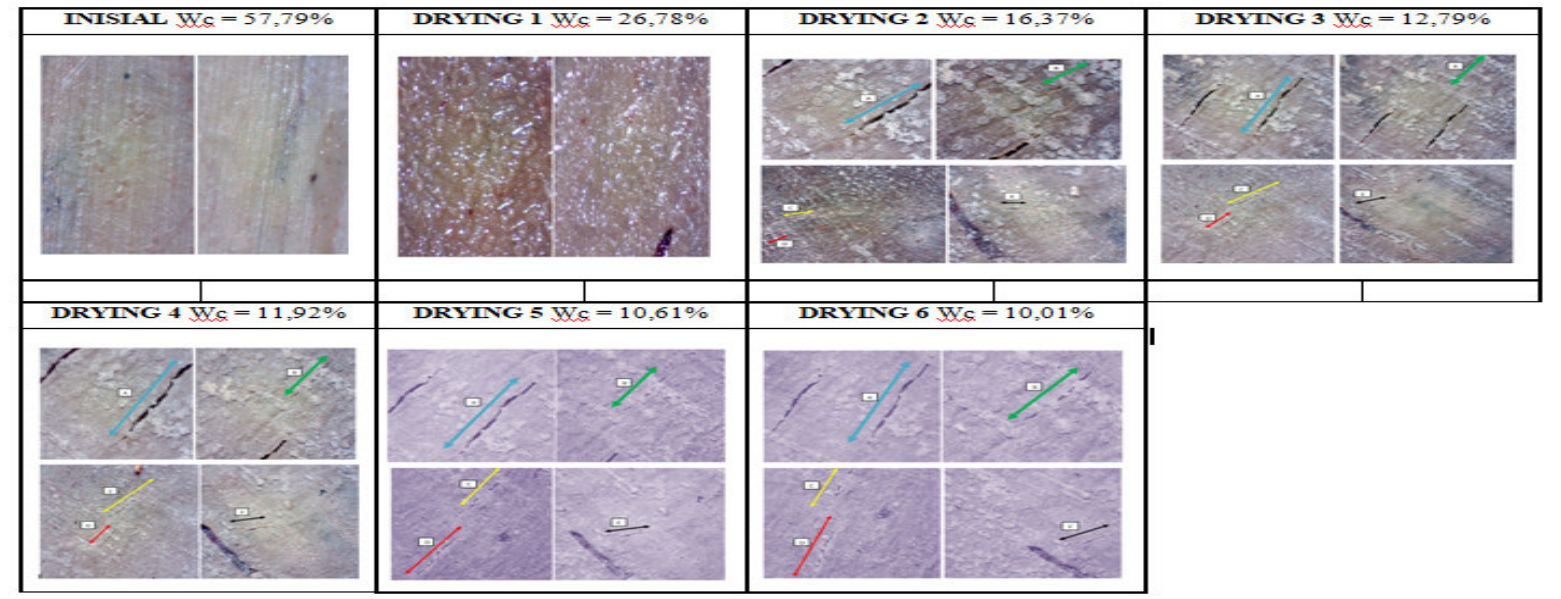

Gambar 2. Foto pengamatan evolusi retak permukaan proses pengeringan dengan menggunakan Mikroskop dan foto digital, pembesaran $200 \mathrm{x}$.

Retak permukaan terjadi pada kondisi drying 2 (lihat gambar 2), pada kadar air 16,3\% terjadi peningkatan nilai suction 178 kali dari kondisi inisial, benda uji pada fase solid saat tanah tidak jenuh. Pada kondisi drying 3 sampai akhir dari proses pengeringan tidak terdapat pertambahan retak permukaan secara kuantitas 
tetapi secara kualitas terjadi pertambahan dalam dimensi retak. Hal ini terjadi karena peningkatan nilai suction tidak cukup besar agar retak permukaan terjadi Elim E, Soemitro,R.A.A and Indarto (2019).

Pada proses pembasahan tidak terjadi retakan tetapi benda uji mengalami kerusakan atau kehancuran ditunjukkan pada gambar 3 dan gambar 4. Kerusakan tanah disebabkan oleh 2 keadaan yaitu pada proses pengeringan, tanah telah mengalami retakan yang besar pada permukaan dan cukup merusak benda uji, selanjutnya kerusakan kedua disebabkan oleh swelling, benda uji mengalami pengembangan yang besar sehingga tanah menjadi rusak. Pada kondisi ini tanah mempunyai kekuatan yang paling lemah. Hal ini diindikasikan oleh parameter sifat fisik dan mekanikal yang terendah Chen Fu Hua (1975) dan Elim E, Soemitro,R.A.A and Indarto (2019). Kadar air inisial dari tanah lempung ekspansif sangat menentukan besarnya pengembangan yang terjadi Holtz,W. G. and Gibbs,J.J (1956), Indarto (2012) dan Seed (1962).
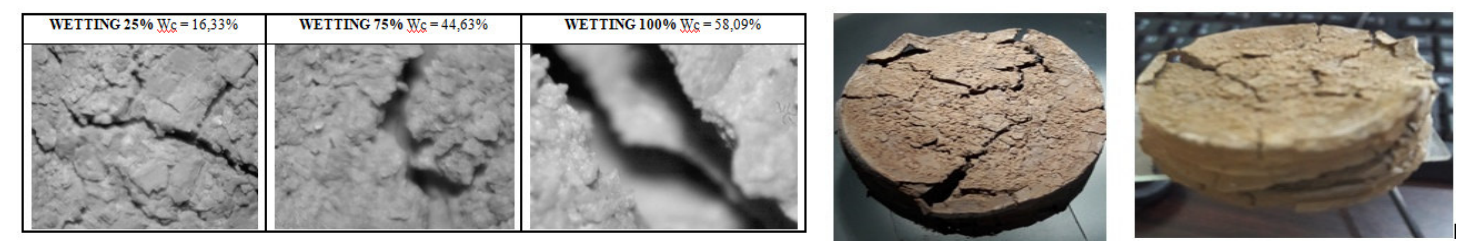

Gambar 3. Foto retak permukaan proses wetting dan benda uji mengalami kerusakan akibat pembasahan

Perubahan volume benda uji secara visual akibat proses pengeringan dan pembasahan ditunjukkan pada gambar 5. Gambar 5.a. menunjukkan benda uji saat inisial ukuran diameter $3,8 \mathrm{~cm}$ tebal $1 \mathrm{~cm}$ volume benda uji $11,83 \mathrm{~cm}^{3}$. Gambar 5.b. Pada kondisi akhir proses pengeringan terjadi penyusutan pada benda uji volume benda uji menjadi $7,25 \mathrm{~cm}^{3}$ atau terjadi penyusutan $38 \%$. Pada kondisi akhir pembasahan terjadi pengembangan volume benda uji menjadi $17 \mathrm{~cm}^{3}$ atau terjadi pengembangan sebesar $57 \%$, terlihat kondisi tanah yang telah rusak Elim E, Soemitro,R.A.A and Indarto (2019).

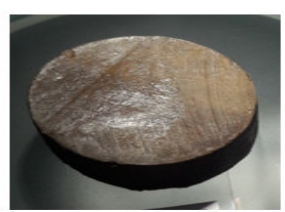

a.

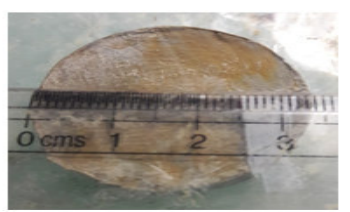

b.

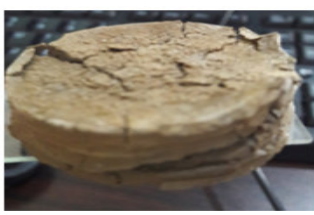

c.

Gambar 5. Foto perubahan volume benda uji. a. Benda uji kondisi inisial b. Benda uji kondisi drying 6 c. Benda uji kondisi wetting $100 \%$

Nilai Undrained Strength pada pengujian Triaksial UU

Table 2. Soil cohesion due to drying-wetting process

\begin{tabular}{cccc}
\hline Condition & Water Content, $\mathrm{w}_{\mathrm{c}}(\%)$ & Cohesion, $\mathrm{c}_{\mathrm{u}}(\mathrm{kPa})$ & Angle of internal friction $\phi($ degree $)$ \\
\hline Initial & 57.79 & 26.77 & 5,20 \\
Drying 1 & 26.78 & 42.07 & 44,10 \\
Drying 2 & 16.37 & 39.62 & 60,80 \\
Drying 3 & 12.79 & & \\
Drying 4 & 11.92 & 26.67 & 62,60 \\
Drying 5 & 10.61 & $*$ & $*$ \\
Drying 6 & 10.01 & 23.24 & 30,40 \\
Wetting 25\% & 16.33 & 28.63 & 4,20 \\
Wetting 75\% & 44.63 & 17.85 & 2,2 \\
Wetting 100\% & 58.09 & & \\
Catatan: * Hasil pengujian Triaxial tidak dapat dilanjutkan karena kapasitas alat tidak mencukupi untuk menekan \\
benda uji yang telah mengeras.
\end{tabular}


Hasil pengujian undrained shear strength ditunjukkan pada tabel 2 direpresentasikan pada Gambar 5. menunjukkan kohesi maksimum proses pengeringan pada kadar air 22\% sebesar $43 \mathrm{kPa}$ dan pada kadar air $45 \%$ sebesar $28 \mathrm{kPa}$ saat pembasahan. Pada kadar air optimum berat unit kering maksimum sebesar $\gamma_{\mathrm{d}}$ $\max =1,57 \mathrm{gr} / \mathrm{cc}$ pada saat pengeringan dan $\gamma_{\mathrm{d} \max }=1,14 \mathrm{gr} / \mathrm{cc}$ saat pembasahan. Hasil dari kadar air optimum pada proses pengeringan berbeda dengan proses pembasahan ini disebabkan karena pada saat pembasahan struktur tanah telah menjadi rusak sehingga kohesi undrained saat proses pembasahan menjadi lebih kecil dari proses pengeringan Elim E, Soemitro,R.A.A and Indarto (2019). Kekuatan geser tanah lempung secara bertahap akan meningkat karena dikeringkan dari kadar air awal diatas batas cair Atkinson, (1978).

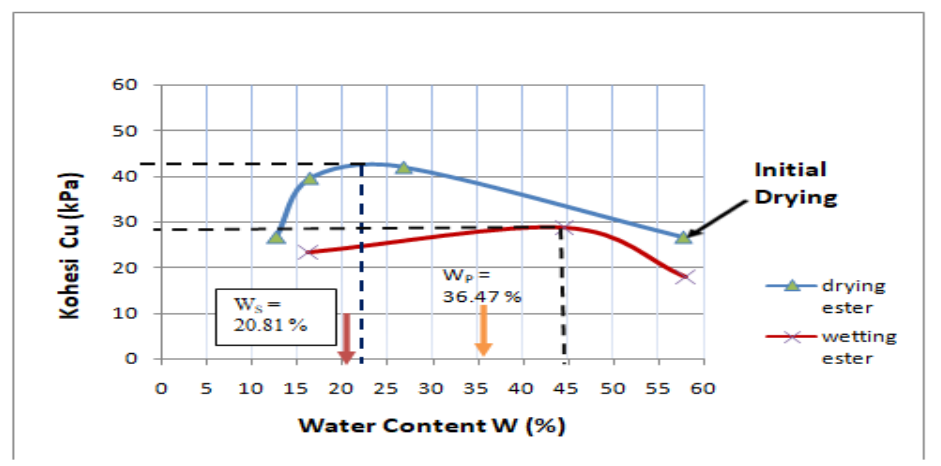

Gambar 5. Grafik hasil pengujian Triaksial untuk nilai kohesi

Terjadi perubahan perilaku tanah ekspansif yaitu penurunan kekuatan geser tanah pada saat tanah pada fase solid, hal ini disebabkan tanah lempung telah berubah menjadi getas sehingga menurunkan kekuatan geser.

Hubungan antara Sudut Geser dalam $(\phi)$ dan Kadar Air

Perubahan kadar air menyebabkan perubahan perilaku kekuatan geser tanah, hasil pengujian sudut geser dalam $(\phi)$ ditunjukkan pada tabel 2. dan direpresentasikan pada gambar 6. Saat pengeringan terjadi keniakn sudut geser sebesar $62,60^{\circ}$ yang melampaui sudut geser dalam $(\phi)$ tanah lempung pada umumnya, hal ini menunjukkan telah terjadi perubahan sifat dari tanah lempung ekspansif menjadi batuan. Sudut geser dalam ( $\phi)$ adalah sekitar $8^{0}$ untuk tanah dengan kandungan clay sebesar 68\% Bowles, Joseph, E. 1979 [3] sedangkan untuk batuan granit nilai sudut geser dalam adalah sekitar $45^{\circ}-55^{\circ}$ Burt G Look, 2007. Saat peningkatan kadar air terjadi penurunan nilai sudut geser dalam $(\phi)$ menjadi $2,2^{\circ}$ yang menunjukkan tanah dalam kondisi tidak jenuh (jika tanah jenuh $(\phi)=0$ ) Fredlund D.G, Rahardjo,H \& Fredlund M.D (2012)

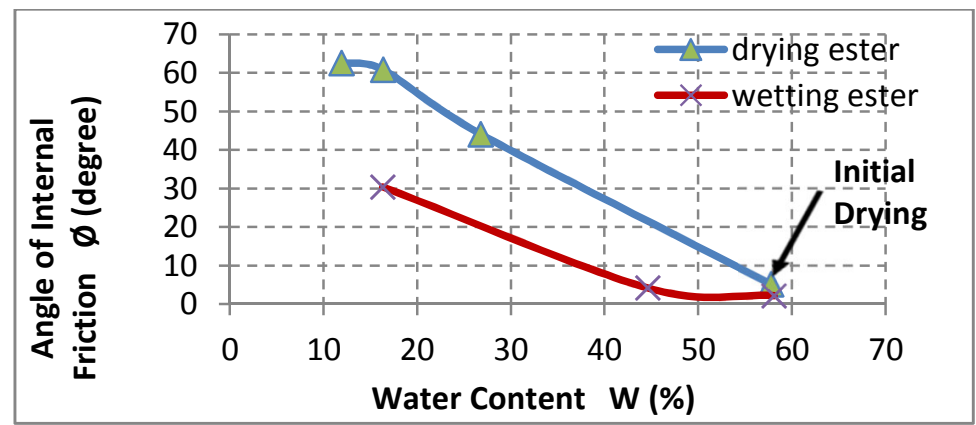

Gambar 6. Grafik hubungan antara Sudut Geser $(\phi)$ dan Kadar Air $(W)$ 


\section{KESIMPULAN}

Dari penelitian ini, dapat disimpulkan sebagai berikut:

1) Pada penelitian ini tidak terjadi histerisis pada Soil Water Characteristic Curve (SWCC). Hal ini disebabkan pada tanah undisturb telah terjadi pengembangan dan penyusutan berulang kali di lapangan, akibat dari perubahan musim panas dan musim hujan, sehingga menurunkan volume pengembangan tanah saat pembasahan.

2) Variasi kadar air pada proses pengeringan dan pembasahan menyebabkan kerusakan (damage) pada tanah. Akibat pengeringan dan pembasahan terjadi 2 kali kerusakan pada tanah, saat pengeringan terjadi retak permukaan yang merusak tanah, saat pembasahan terjadi swelling pada tanah sehingga tanah menjadi hancur. Kekuatan tanah terendah pada kondisi ini.

Sifat tanah lempung ekspansif berubah menyerupai batuan saat dilakukan pengeringan, terdapat kohesi maksimum $43 \mathrm{kPa}$ pada kadar air 22\% saat pengeringan dan $28 \mathrm{kPa}$ pada kadar air $45 \%$

\section{DAFTAR PUSTAKA}

Atkinson, (1978) "The Mechanics of Soils An Introduction to Critical State Soil Mechanics", McGRAWHILL Book Company (UK) Limited, Maidenhead- Berkshire-England, pp 292-307.

Badawi, S and Indarto. (2010) "Behavior of ekspansive Undisturb and Remoulded soil under dryingwetting cycle.” Seminar Nasional VI 2010 Teknik Sipil ITS Surabaya. 105-112.

Bowles, Joseph, E. (1979). "Physical and Geotechnical Properties of Soil”,McGRAW-HILL Book

Burt G Look, (2007). "Handbook of Geotechnical Investigation and Design Tables", Taylor \&

Chen Fu Hua (1975), Foundation on Expansive Soil, Elsevier Publishing Company pp.9-29. Company (UK) Limited, Maidenhead-Berkshire-England.

Elim E, Soemitro,R.A.A and Indarto (2019) "Behaviour of Undisturb Expansive Soil in Citraland Surabaya Through Phase Change Due to Drying and Wetting", Tesis Institut Teknologi Sepuluh Nopember. Surabaya. Indonesia.

Francis Group, London, UK. 29-38.

Fredlund \& Rahardjo, (1993), "Soil Mechanics for Unsaturated Soils". A Willey-interscience publication. John Wiley \& Sons, Inc. 1-19.

Fredlund D.G, Rahardjo,H \& Fredlund M.D, (2012). "Unsaturated Soil Mechanics in Engineering Practice". A Willey-interscience publication. John Wiley \& Sons, Inc. 520-678.

Hall,Inc.,Engelwood Cliffs,NJ. 07632, pp.186-190

Holtz, R.D and Kovacs, W.D (1981) “An Introduction To Geotechnical Engineering”, Prentice-

Holtz,W. G. and Gibbs,J.J (1956) "Engineering Properties of Expansive Clays"ASCE Transaction Paper No. 2814, Vol. 1211956

Indarto, (2012), Kelakukan tanah ekspansif serta akibatnya pada bangunan dan jalan sederhana). ITS Press. Surabaya. 2012.16-37

Seed (1962), H.B,Woodward,R.J. and Lundgren,R., " Prediction of Swelling Potential for Compacted Clays" Journal ASCE, Soil Mechanics and Foundation Div., Vol.88, 1962 